\title{
Perspectives on European Work-related Education, Practice and Research
}

This special issue illustrates WORK's commitment to advance our knowledge base and disseminate knowledge about work-related practice, education and research on an international level. It is a great pleasure to present this multifaceted collection of papers that address work-related issues as relevant to education, clinical and social practice, and research from countries throughout Europe.

This special issue starts off with a sounding board by van Bruggen, Occupational Therapist, and Coordinator of two Social Reform and Teacher Training projects. She reflects on some significant historical developments, the complexity and current challenges that characterize Europe's effort toward social inclusive societies. More specifically, reference is given to the European labor market, current Employment strategies, and the situation of people who are furthest removed of the labor market (e.g. migrants, older worker, people with disability, women). Hanneke van Bruggen encourages health professionals to take an active stake in tackling these challenges and illustrates her arguments through ongoing developments within occupational therapy. In all her examples and elaborations the need to work in partnerships with various stakeholders, including service users, service providers, and governments, to adhere to the changes in the transformative world of work becomes evident.

This sounding board provides valuable background information and insightful reflections on the greater socio-political context of specific educational and community-based programs that are elaborated on in some of the papers within this special issue. Two papers of this selection elaborate on an educational program entitled Euro-Education: Employability for all (EEE4all). This educational program is based on the collaboration of four European countries, namely Germany, the Netherlands, Sweden, and the United Kingdom. Falk, Sandqvist and Liedberg describe in their paper the development of the curriculum for this program geared toward health professionals and designed to promote employability while remaining sensitive on issues of gender, age, disability, and ethnicity. The paper presented in this special issue focuses in particular on the development of the gender-module within this program. Craig and Piskur have devoted their paper also to this educational program and provide a program evaluation. The evaluation reflects the challenges as well as the benefits and value of such an international course that encompasses on-site and distance learning.

The paper by Kantarzis, Breedvelt, Mattijs, Geert, Leonardos, Yiannis, Stefanos and Georgia is a contribution based on the collaboration of mental health service users and professionals from several European countries namely Belgium, Greece, and the Netherlands. Their paper offers insights into this partnership called Empowering Learning for Social Inclusion through Occupation (ELSiTO). The program description focusses on people engaged in a program that aims to facilitate social inclusion. The authors outline the challenges that people may experience in maintaining paid work, along the continuous efforts to engage in meaningful and purposeful occupations that go beyond paid work and include also voluntary work.

The challenge of social inclusion is also addressed by Lysaght, Jakobsen, and Granhaug. Their case study presents a social firm, which is a commercial business situated within a Norwegian community that aims to create employment opportunities for people who experience challenges in their work participation. Social firms are promising in having a significant impact on facilitating the employability of individuals and thus are valuable from an economic and rehabilitation perspective.

Another case-study that has a particular emphasis on vocational rehabilitation is presented from a group of Swiss researchers, namely Glässel, Rauch, Selb, 
Emmenegger, Lückenkemper, and Escorpizo. This group of authors illustrates the usefulness of documentation based on the International Classification of Functioning, Disability, and Health (ICF) in an interdisciplinary rehabilitation setting in Switzerland as illustrated through the case of a young man with spinal cord injury.

As the guest-editors of this section of the special issue we hope that you enjoy the variety of these papers that offer some glimpses into the scope and some current trends of work-related practices in education, clinical and social practice and research throughout Europe.

Guest Editors

Birgit Prodinger Institute for Advanced Studies in Social Ethics Mönchsberg 2A
5020 Salzburg

Austria

E-mail: bprodinger@ifz-salzburg.at

Lynn Shaw

1201 Western Road

Elborn College, Room 2542

School of Occupational Therapy

The University of Western Ontario

London, Ontario

N6G 1H1 Canada

E-mail: leshaw@uwo.ca

Hanneke van Bruggen

Jachthoornlaan 8

7312CE Apeldoorn

The Netherlands

E-mail: j.e.van.bruggen@gmail.com 